\title{
Efficient Photocatalytic Hydrogen Evolution via Band Alignment Tailoring: Controllable Transition from Type-I to Type-II
}

\author{
Zhongzhou Cheng, Fengmei Wang, Tofik Ahmed Shifa, Chao Jiang, Quanlin Liu, and Jun He*
}

Considering the sizable band gap and wide spectrum response of tin disulfide $\left(\mathrm{SnS}_{2}\right)$, ultrathin $\mathrm{SnS}_{2}$ nanosheets are utilized as solar-driven photocatalyst for water splitting. Designing a heterostructure based on $\mathrm{SnS}_{2}$ is believed to boost their catalytic performance. Unfortunately, it has been quite challenging to explore a material with suitable band alignment using $\mathrm{SnS}_{2}$ nanomaterials for photocatalytic hydrogen generation. Herein, a new strategy is used to systematically tailor the band alignment in $\mathrm{SnS}_{2}$ based heterostructure to realize efficient $\mathrm{H}_{2}$ production under sunlight. A Type-I to Type-II band alignment transition is demonstrated via introducing an interlayer of $\mathrm{Ce}_{2} \mathrm{~S}_{3}$, a potential photocatalyst for $\mathrm{H}_{2}$ evolution, between $\mathrm{SnS}_{2}$ and $\mathrm{CeO}_{2}$. Subsequently, this heterostructure demonstrates tunability in light absorption, charge transfer kinetics, and material stability. The optimized heterostructure $\left(\mathrm{SnS}_{2}-\mathrm{Ce}_{2} \mathrm{~S}_{3}-\mathrm{CeO}_{2}\right)$ exhibits an incredibly strong light absorption ranging from deep UV to infrared light. Significantly, it also shows superior hydrogen generation with the rate of $240 \mu \mathrm{mol} \mathrm{g}^{-1} \mathrm{~h}^{-1}$ under the illumination of simulated sunlight with a very good stability.

\section{Introduction}

Owing to its renewable solar energy source, photocatalytic hydrogen evolution by water splitting has been considered as a promising research for clean energy technology in scientific communities. ${ }^{[1]}$ The effectiveness in this endeavor is associated with a great effort of improving the semiconductor's capabilities via enabling the absorption of tremendous portion of solar energy and suppressing the rapid recombination of photogenerated

Z. Z. Cheng, Prof. C. Jiang, Prof. Q. L. Liu

School of Materials Science and Engineering

University of Science and Technology

Beijing 100083, China

Z. Z. Cheng, Dr. F. M. Wang, T. A. Shifa, Prof. J. He

CAS Center for Excellence in Nanoscience

CAS Key Laboratory of Nanosystem and Hierarchical Fabrication

National Center for Nanoscience and Technology

Beijing 100190, China

E-mail: hej@nanoctr.cn

Dr. F. M. Wang, T. A. Shifa

University of Chinese Academy of Sciences

Beijing 100049, China

The ORCID identification number(s) for the author(s) of this article can be found under https://doi.org/10.1002/smll.201702163.

DOI: 10.1002/smll.201702163 electron-hole pairs. ${ }^{[2]}$ To satisfy these two requirements simultaneously is one of the biggest challenges. In this regard, compared with the single component photocatalysts like $\mathrm{TiO}_{2},{ }^{[2,3]} \mathrm{ZnO},{ }^{[4]}$ and $\mathrm{CdS},{ }^{[5]}$ constructing well-aligned heterostructures is considered as an effective way to overcome these problems. ${ }^{[6]}$ In general, there are three types of heterostructures (Type-I, II, and III) according to the relative positions of conduction band (CB) and valence band (VB) in the respective semiconductors. Usually, straddling types (Type-I) are formed between many materials. Although absorption is greatly enhanced in the case of Type-I, it is associated with significant rate of recombination which is detrimental for photocatalysis. In the case of Type-II, its staggered arrangement prolongs the lifetime of photoinduced electrons and holes, thereby inhibiting the rate of recombination. The design of Type-II heterostructures is, therefore, considered as an ideal feature for photocatalysis. As consequence, shifts from Type-I to Type-II band alignment greatly widen the horizon of materials' application in photocatalysis. The absorption range can be extended to visible light and even to infrared light via band alignment transition from Type-I to Type-II, while retaining such a scheme that prolongs the lifetime of charge carriers and suppresses their recombination.

Due to their high specific surface area, ultrathin 2D materials $^{[7]}$ are widely investigated for photochemical reactions. ${ }^{[8]}$ Currently, considerable progresses that communicated the features of $2 \mathrm{D}$ materials like graphene, ${ }^{\left[{ }^{[]}\right.} \mathrm{MoS}_{2},{ }^{[10]}$ and $\mathrm{C}_{3} \mathrm{~N}_{4}{ }^{[11]}$ have been made for water splitting. Of particular note is that, hexagonal tin disulfide $\left(\mathrm{SnS}_{2}\right)$ attracts the interests of researchers on account of its fast light response, ${ }^{[12]}$ chemical stability, suitable band gap ${ }^{[13]}\left(E_{\mathrm{g}} \approx 2.4 \mathrm{eV}\right)$, as well as its easy preparation routes. Different morphologies of $\mathrm{SnS}_{2}$ nanostructures have been reported for photocatalytic water splitting and promising results were exhibited. ${ }^{[14]}$ Thus, it is quite reasonable to expect boosted performance in water splitting provided that appropriate material is sought to construct the heterostructure based on $\mathrm{SnS}_{2}$. In this respect, cerium sulfide $\left(\mathrm{Ce}_{2} \mathrm{~S}_{3}\right)$ $\left(E_{\mathrm{g}} \approx 2.1 \mathrm{eV}\right)$ is a promising alternative as it possesses perfect band edge positions for water splitting as well as for alignment with $\mathrm{SnS}_{2}$. ${ }^{[15]}$ The $\mathrm{CB}$ and $\mathrm{VB}$ of $\mathrm{Ce}_{2} \mathrm{~S}_{3}$ were reported to be -0.78 and $1.32 \mathrm{eV}$, respectively. ${ }^{[15]}$ The high negative potential of $\mathrm{CB}$ indicates that the $\mathrm{Ce}_{2} \mathrm{~S}_{3}$ is an ideal visible light photocatalyst 
for the water splitting. However, it is challenging to ensure the chemical stability of $\mathrm{Ce}_{2} \mathrm{~S}_{3}$ in aqueous solution because of its hygroscopicity. Thus, it is highly essential to design a route for establishing a Type-II alignment between $\mathrm{SnS}_{2}$ and $\mathrm{Ce}_{2} \mathrm{~S}_{3}$ despite the chemical instability of $\mathrm{Ce}_{2} \mathrm{~S}_{3}$.

Herein, we report a two-step strategy for synthesizing such a heterostructure. Vertically aligned ultrathin $\mathrm{SnS}_{2}$ nanosheets were uniformly grown on carbon fiber (CF) through solvothermal method.[16] And then, $\mathrm{Ce}_{2} \mathrm{~S}_{3}$ nanoribbons and $\mathrm{CeO}_{2}$ nanoparticles were successively formed on the surface of the $\mathrm{SnS}_{2}$ nanosheets after immersing the as prepared $\mathrm{SnS}_{2}$ nanosheets in the solution containing cerium nitrate and hexamethylenetetramine (HMT) with little addition of thioacetamide for the second step solvothermal reaction. The control of reaction time $(6-24 \mathrm{~h})$ in the second step of hydrothermal reaction brought different features on the surface of $\mathrm{SnS}_{2}$ nanosheet as corroborated from series of X-ray diffraction patterns and Raman spectra. Interestingly, a suitable protective layer of ceria $\left(\mathrm{CeO}_{2}\right)\left(E_{\mathrm{g}} \approx 3.2 \mathrm{eV}\right)$ with good chemical stability is found to protect $\mathrm{Ce}_{2} \mathrm{~S}_{3}$, in the ultimately synthesized sandwiched structure of $\mathrm{SnS}_{2}-\mathrm{Ce}_{2} \mathrm{~S}_{3}-\mathrm{CeO}_{2}$. The content ratio of $\mathrm{Ce}_{2} \mathrm{~S}_{3}$ and $\mathrm{CeO}_{2}$ can be tuned via controlling the reaction time. With such reasonably built heterostructure, our system can realize a wide range of absorption ranging from 250 to $1000 \mathrm{~nm}$. Notably, it shows superior hydrogen generation with the rate of $240 \mu \mathrm{mol} \mathrm{g}^{-1} \mathrm{~h}^{-1}$ under illumination of simulated sunlight.

\section{Results and Discussion}

The morphologies of the material at various reaction steps are characterized through scanning electron microscope (SEM) image (Figure 1a-c) whose insets represent the schematic of the process undergone. We found reaction time to be crucially important parameter and the various reaction steps are designated as T6-T24 based on how long (hour) the hydrothermal reaction took. As can be seen in Figure 1a (Step 1), the ultrathin nanosheets of $\mathrm{SnS}_{2}$ with a smooth surface appear to be vertically standing nanosheets. The thickness of a single nanosheet can be estimated as $6 \mathrm{~nm}$ based on the observation from atomic force microscopy image (Figure S1, Supporting Information). Then, the ultrathin $\mathrm{Ce}_{2} \mathrm{~S}_{3}$ nanoribbons are evenly formed on the surface of $\mathrm{SnS}_{2}$ nanosheets as shown in Figure 1b (Step 2), which is a critical step for synthesizing the desired ternary heterojunction. As the reaction time prolongs, the as-grown $\mathrm{Ce}_{2} \mathrm{~S}_{3}$ nanoribbon got covered by $\mathrm{CeO}_{2}$ nanoparticles, making a sandwiched ternary structure of $\mathrm{SnS}_{2}-\mathrm{Ce}_{2} \mathrm{~S}_{3}-\mathrm{CeO}_{2}$ system where in the stability issue of $\mathrm{Ce}_{2} \mathrm{~S}_{3}$ is no longer a problem. A ball and stick model is depicted in Figure $1 \mathrm{~d}$ to visualize the crystal structure of $\mathrm{SnS}_{2}-\mathrm{Ce}_{2} \mathrm{~S}_{3}-\mathrm{CeO}_{2}$ which demonstrates the way the components are arranged in the heterostructure. The presence of $\mathrm{Ce}_{2} \mathrm{~S}_{3}$ brings a very interesting phenomenon. The advent of two kinds of Type-II heterojunctions $\left(\mathrm{SnS}_{2}-\mathrm{Ce}_{2} \mathrm{~S}_{3}\right.$ and $\mathrm{Ce}_{2} \mathrm{~S}_{3}-\mathrm{CeO}_{2}$ ) can be understood from Figure 1f, which otherwise would have been a mere of Type-I $\left(\mathrm{SnS}_{2}\right.$ and $\left.\mathrm{CeO}_{2}\right)$ system a

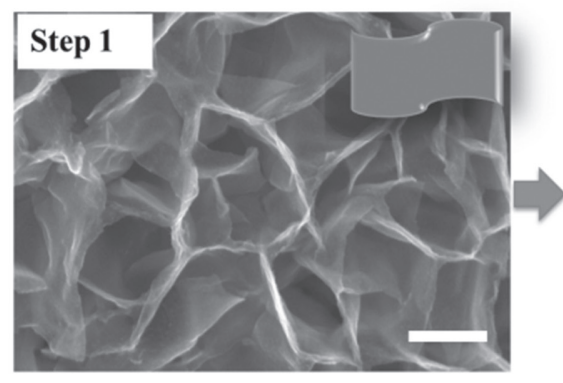

d

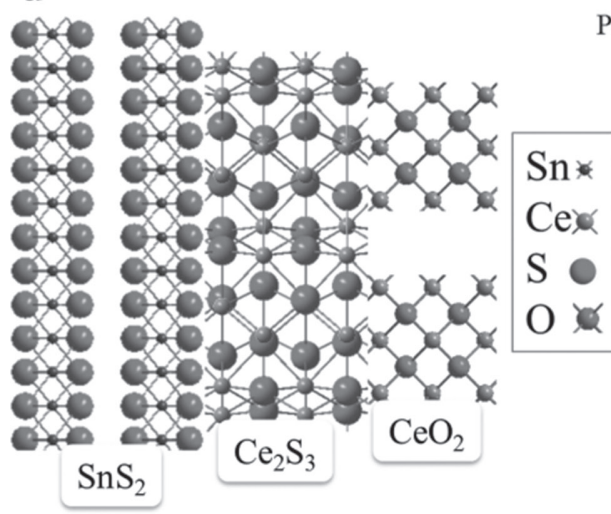

b

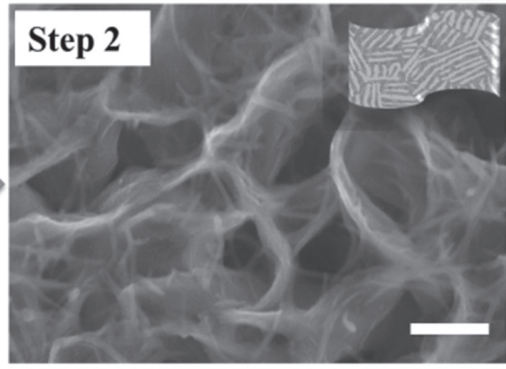

$\mathbf{e}$

Potential versus NHE (V)

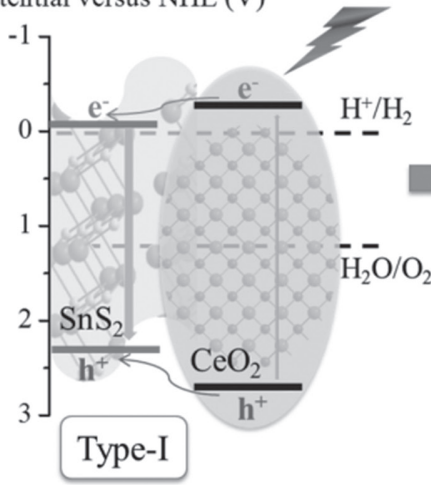

C

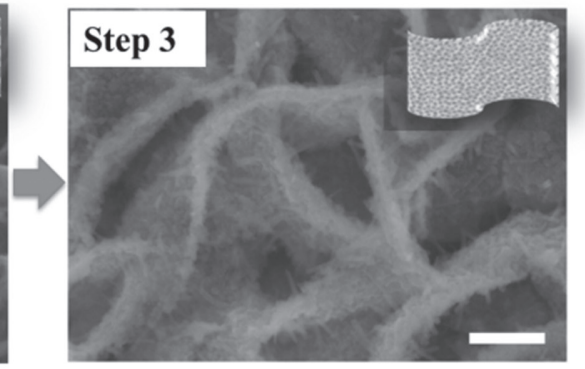

f

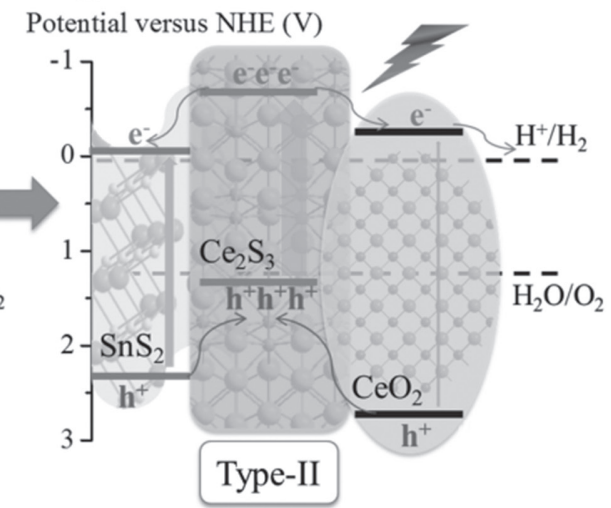

Figure 1. Morphologies and band alighment analysis of diffirent photocatalysts. Preparation process of the ternary heterojunction on carbon fiber (CF) substrate. Scanning electron microscopy (SEM) images of the a) step 1: $\mathrm{SnS}_{2}$ nanosheet, b) step 2: $\mathrm{SnS}_{2}-\mathrm{Ce}_{2} \mathrm{~S}_{3}$ structure, and c) step 3: $\mathrm{SnS} \mathrm{S}_{2}-\mathrm{Ce}_{2} \mathrm{~S}_{3}-\mathrm{CeO}_{2}$ system. Scale bars: $500 \mathrm{~nm}$, insets: brief schematic diagrams. d) The structure of the heterojunction. And the band structure of the system, e) a Type-I structure between $\mathrm{SnS}_{2}$ and $\mathrm{CeO}_{2}$ without the $\mathrm{Ce}_{2} \mathrm{~S}_{3}$, f) Type-II structures with the $\mathrm{Ce}_{2} \mathrm{~S}_{3}$ as the intermediate layer. 

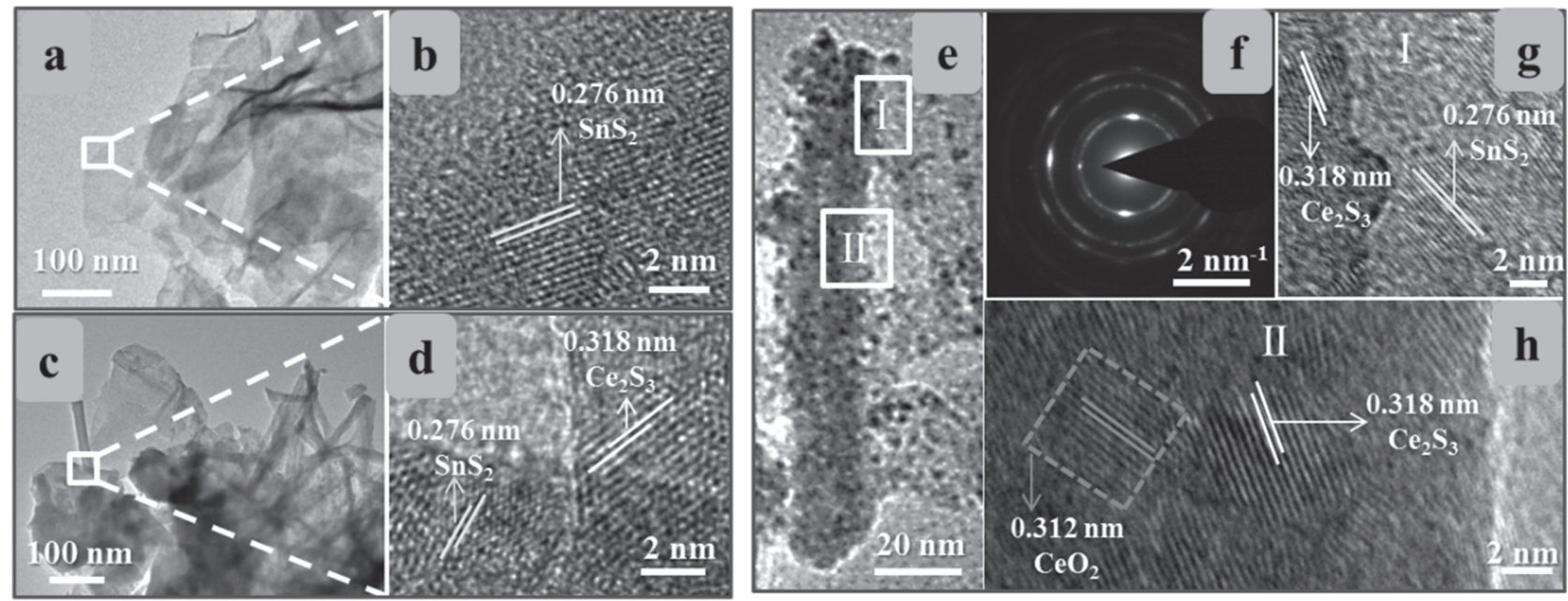

Figure 2. TEM measurments of the samples. The transmission electron microscopy (TEM) image and high-resolution transmission electron microscopy (HRTEM) images of a,b) the step 1: $\mathrm{SnS}_{2}$ nanosheet, c,d) step 2: $\mathrm{SnS}_{2}-\mathrm{Ce}_{2} \mathrm{~S}_{3}$ structure, and e-h) step 3: $\mathrm{SnS}_{2}-\mathrm{Ce}_{2} \mathrm{~S}_{3}-\mathrm{CeO}_{2}$ system. For more information, please see Figures S2 and S3 in the Supporting Information.

in the absence of $\mathrm{Ce}_{2} \mathrm{~S}_{3}$ (Figure 1e). Therefore, a shift from Type-I to Type-II band alignment is realized, thus enhancing the absorption of visible light and increasing the efficiency of photocatalytic hydrogen production from water.

The crystallographic features of the components makingup the heterostructure can be investigated using transmission electron microscopy (TEM) and high-resolution transmission electron microscopy (HRTEM) (Figure 2a-h). The ultrathin nature of $\mathrm{SnS}_{2}$ nanosheets (obtained via Step 1 process) can be more clearly identified from low-magnification TEM image (Figure 2a). Moreover, a lattice fringe of $0.276 \mathrm{~nm}$ belonging to the plane (011) of $\mathrm{SnS}_{2}$ is evidenced from HRTEM image, which is shown in Figure 2b. As can be seen in Figure 2c, there is a distinct feature in $\mathrm{SnS}_{2}-\mathrm{Ce}_{2} \mathrm{~S}_{3}$ (obtained via Step 2 process) following the growth of numerous nanoribbons (about $20 \mathrm{~nm}$ in diameter) on the nanosheets. Here, the morphologies of nanoribbons and nanosheets correspond to $\mathrm{Ce}_{2} \mathrm{~S}_{3}$ and $\mathrm{SnS}_{2}$, respectively. More insight analysis from HRTEM image (Figure 2d) solidifies the above statement from the corroboration of lattice fringes in the nanosheet $(0.276 \mathrm{~nm})$ which can be indexed to hexagonal $\mathrm{SnS}_{2}$ and that in the nanoribbon area $(0.318 \mathrm{~nm})$ can be indexed to orthorhombic $\mathrm{Ce}_{2} \mathrm{Se}_{3}$. After Step 3, the nanoribbons are decorated with lots of nanoparticles whose average size is below $5 \mathrm{~nm}$ (Figure 2e; Figure S2, Supporting Information). Different regions are marked as I and II for subsequent characterizations. Selected area electron diffraction (SAED) rings (Figure 2f) indicate the polycrystalline structure of the system. The corresponding HRTEM images are demonstrated in Figure 2g-h and Figure S3 (Supporting Information). The space fringes of $0.276 \mathrm{~nm}$ (Figure $2 \mathrm{~g}$ ) can be indexed to the plane (011) of hexagonal $\mathrm{SnS}_{2}$ and the $0.318 \mathrm{~nm}$ to the plane of (031) orthorhombic $\mathrm{Ce}_{2} \mathrm{~S}_{3}$, suggesting the existence of $\mathrm{SnS}_{2}$ and $\mathrm{Ce}_{2} \mathrm{~S}_{3}$ entities at this stage as well. It is worth noting that a clear lattice space fringe of $0.312 \mathrm{~nm}$ appears in Figure $2 \mathrm{~h}$ which can be indexed to the plane (111) of cubic $\mathrm{CeO}_{2}$. Thus, successful construction of heterojunctions can be evidenced by the observation of sharp interfaces between $\mathrm{SnS}_{2}$ nanosheets and $\mathrm{Ce}_{2} \mathrm{~S}_{3}$ nanoribbons; as well as between $\mathrm{Ce}_{2} \mathrm{~S}_{3}$ nanoribbon and $\mathrm{CeO}_{2}$ nanoparticles. Further crystallographic information was extracted from X-ray diffraction (XRD) patterns (Figure 3a). For pure $\mathrm{SnS}_{2}$ grown on $\mathrm{CF}$, diffraction peaks that are found at $2 \theta$ values of $14.98^{\circ}, 28.68^{\circ}, 32.40^{\circ}$, and $50.44^{\circ}$ (marked with the symbol $\square$ ) can be indexed to the planes (001), (100), (002), and (110) of hexagonal $\mathrm{SnS}_{2}$ (The International Centre for Diffraction Data, called as ICDD, PDF\#75-0367), respectively. The XRD pattern of pure $\mathrm{CeO}_{2}$ (marked with the symbol $\circ$ ) is also provided for ease of comparison (ICDD, PDF\#43-0394). Except for the peaks of pure $\mathrm{CeO}_{2}$, there are other peaks at $26.28^{\circ}$, $31.60^{\circ}, 39.22^{\circ}, 43.38^{\circ}$, and $51.20^{\circ}$ (marked with the symbol $\diamond$ ) for the samples of T6, T15, and T24. This peaks can be assigned to the orthorhombic $\mathrm{Ce}_{2} \mathrm{~S}_{3}$ phase (ICDD, PDF\#43-0799). Interestingly, the relative intensity of the XRD peaks of $\mathrm{CeO}_{2}$ and $\mathrm{Ce}_{2} \mathrm{~S}_{3}$ varies depending on the reaction time, which means that the change of the relative content of the $\mathrm{Ce}_{2} \mathrm{~S}_{3}$ and $\mathrm{CeO}_{2}$ in this heterostructure is related to how long the hydrothermal reaction is set to proceed.

In order to determine the composition of the system, Raman spectra were obtained for different samples and the result is depicted in Figure $2 \mathrm{~b}$. The prominent Raman peaks featuring pristine $\mathrm{SnS}_{2}, \mathrm{CeO}_{2}$, and $\mathrm{Ce}_{2} \mathrm{~S}_{3}$ appear at $313 \mathrm{~cm}^{-1}$ (A $A_{1 g}$ mode), ${ }^{[17]} 453 \mathrm{~cm}^{-1}$ ( $F_{2 g}$ mode), ${ }^{[18]}$ and $225 \mathrm{~cm}^{-1}$ ( $E_{g}$ mode), ${ }^{[19]}$ respectively. Notably, the variety in intensity of the peaks at 225 and $453 \mathrm{~cm}^{-1}$ for T6, T15, and T24 can be related to the extent of growth for $\mathrm{CeO}_{2}$ on the surface of $\mathrm{Ce}_{2} \mathrm{~S}_{3}$. The sharp peak observed at $225 \mathrm{~cm}^{-1}$ for T6 decreased in intensity with increase of reaction time and eventually disappeared for the case of T24. On the contrary, the peak at $453 \mathrm{~cm}^{-1}$ is gradually observed for the corresponding samples, evidencing the formation of $\mathrm{CeO}_{2}$. Obviously, there is slight shift in the position of the peak for $\mathrm{SnS}_{2}$ after $\mathrm{Ce}_{2} \mathrm{~S}_{3}$ nanoribbons are grown on the surface of $\mathrm{SnS}_{2}$ nanosheet. The above results powerfully confirm that optimum composition of the heterostructure can be obtained by mere control of the growth time. To further confirm the components on surface matrix, we conducted 

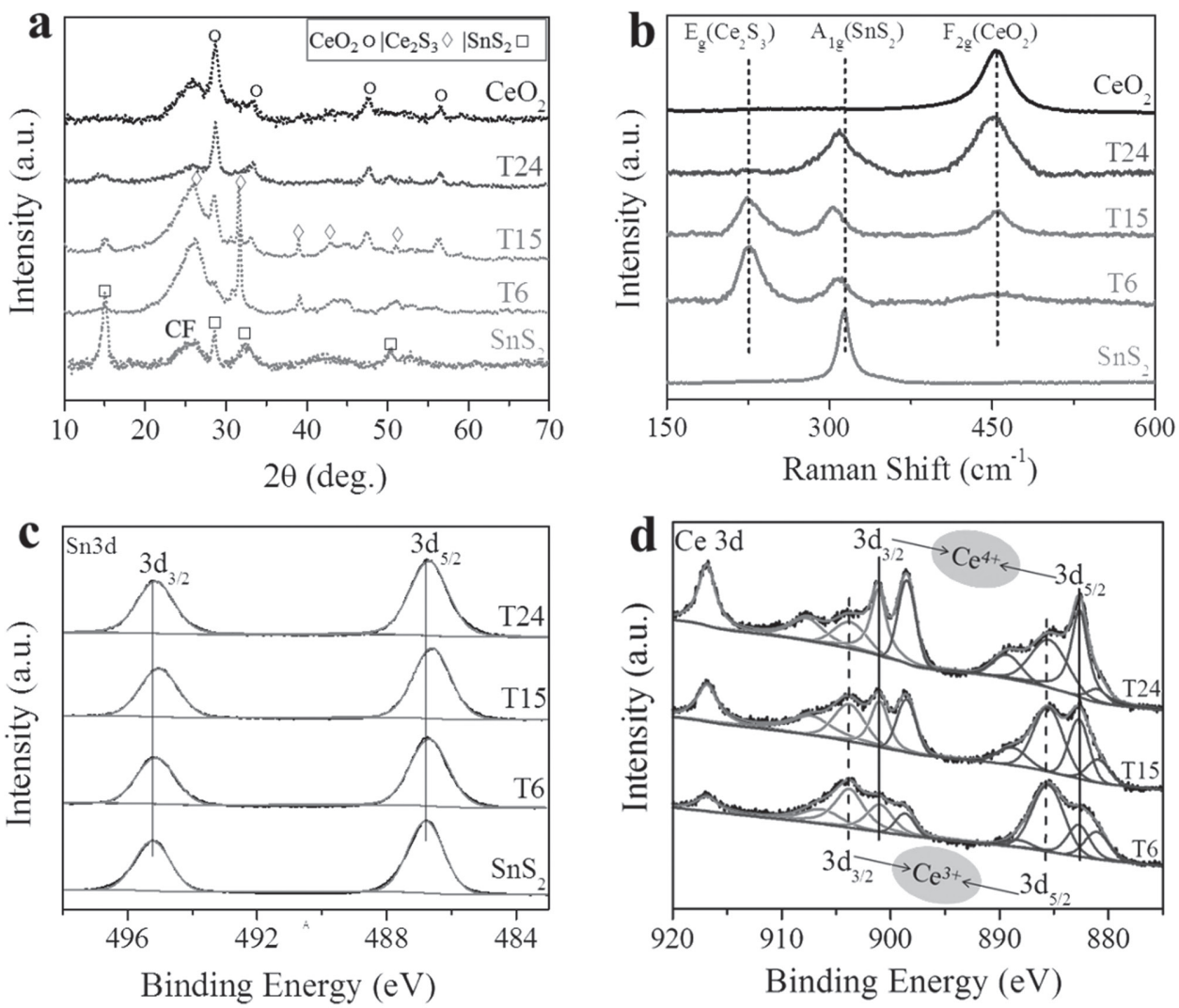

Figure 3. XRD, Raman, and XPS analysis of different samples. a) X-ray diffraction (XRD) pattern and b) Raman spectra of the different samples. High-resolution X-ray photoelectron spectroscopy (XPS) spectra of c) Sn 3d and d) Ce 3d regions.

X-ray photoelectron spectroscopy (XPS) analysis for different samples. Accordingly, Figure $3 \mathrm{c}$ shows that there are slight changes on the signals for $\operatorname{Sn} 3 \mathrm{~d}_{3 / 2}$ and $3 \mathrm{~d}_{5 / 2}$ with different course of reaction time. This corroborates the fact that the chemical state of $\mathrm{SnS}_{2}$ is almost kept unaffected besides a light doping impact. Due to the hybridization of Ce $6 \mathrm{~s}$ and $5 \mathrm{~d}$ valence orbitals, Ce has various oxidation states, in which +3 and +4 are known to be the two characteristic oxidation states. Figure 3d shows the high-resolution XPS spectra, along with the satellite peaks in Ce $3 \mathrm{~d}$ region which contains primarily $\mathrm{Ce}^{3+}(903.8 \mathrm{eV}$ for $3 \mathrm{~d}_{3 / 2}$ and $885.3 \mathrm{eV}$ for $\left.3 \mathrm{~d}_{5 / 2}\right)$ and $\mathrm{Ce}^{4+}\left(901.2 \mathrm{eV}\right.$ for $3 \mathrm{~d}_{3 / 2}$ and $882.7 \mathrm{eV}$ for $3 \mathrm{~d}_{5 / 2}$ ), corresponding to $\mathrm{Ce}_{2} \mathrm{~S}_{3}$ and $\mathrm{CeO}_{2}$, respectively. Upon critical comparison of Ce $3 \mathrm{~d}$ region for $\mathrm{T} 6$, $\mathrm{T} 15$, and T24, the intensity of the peaks for $\mathrm{Ce}^{3+}$ decrease while that of $\mathrm{Ce}^{4+}$ increases with extended reaction time. This further solidifies the discussion made above for Raman and XRD characterization with respect to the variation in the content of $\mathrm{Ce}_{2} \mathrm{~S}_{3}$ and $\mathrm{CeO}_{2}$. Thus, the ratio of $\mathrm{Ce}_{2} \mathrm{~S}_{3}$ and $\mathrm{CeO}_{2}$ could be tuned by the reaction time. From the deconvolution of the XPS spectra, the quantitative content of $\mathrm{Ce}^{3+}$ and $\mathrm{Ce}^{4+}$ varies from 2.65:1 to 0.88:1 (Table S1, Supporting Information). Moreover, the atomic percentages of the various elements such as $\mathrm{Ce}, \mathrm{Sn}, \mathrm{S}$, and $\mathrm{O}$ were obtained from the XPS analysis, shown in Table S2 (Supporting Information). From Tables S1 and S2 (Supporting Information), the atomic percentages of $\mathrm{Sn}, \mathrm{Ce}^{3+}$, and $\mathrm{Ce}^{4+}$ were obtained. Then the weight ratios of $\mathrm{SnS}_{2}, \mathrm{Ce}_{2} \mathrm{~S}_{3}$, and $\mathrm{CeO}_{2}$ for different samples were calculated in Table S3 (Supporting Information).
The light harvesting capacities of the as-synthesized nanomaterials were investigated through UV/Vis/NIR absorption spectra, extracted from the diffuse reflectance spectra. As it is well known, information about the band gap of the photocatalyst is crucial for understanding the energetics of the reactions. To this end, we first extracted Kubelka-Munk function $(F(R))$ from the diffuse reflectance measurement by using the following equation to obtain absorption coefficient $(\alpha):{ }^{[20]}$

$F(R)=\frac{(1-R)^{2}}{2 R}=\frac{\alpha}{S}$

Where, $F(R)$ is the Kubelka-Munk function, $R$ is reflectance, and $s$ is scattering coefficient. For band gap energy $\left(E_{\mathrm{g}}\right)$ calculation, the Tauc plots (Figure 4a) were analyzed by extrapolating $(\alpha h v)^{2}$ versus photon energy $(h v)$ using the following equation: ${ }^{[21]}$

$\alpha h v=A\left(h v-E_{\mathrm{g}}\right) n / 2$

Where, $\alpha$ is the absorption coefficient, $A$ is a constant. Here, $n$ depends on the characteristics of the transition in a semiconductor (direct transition $n=1$ and indirect transition $n=4)$. In our case, $\mathrm{Ce}_{2} \mathrm{~S}_{3}, \mathrm{SnS}_{2}$, and $\mathrm{CeO}_{2}$ all are characterized by strong absorption of band edges, which indicate the direct transition semiconductors, ${ }^{[14 b, 22]}$ and hence we assume $n$ value of 1 throughout the calculation. In the Tauc plot, the intercept 

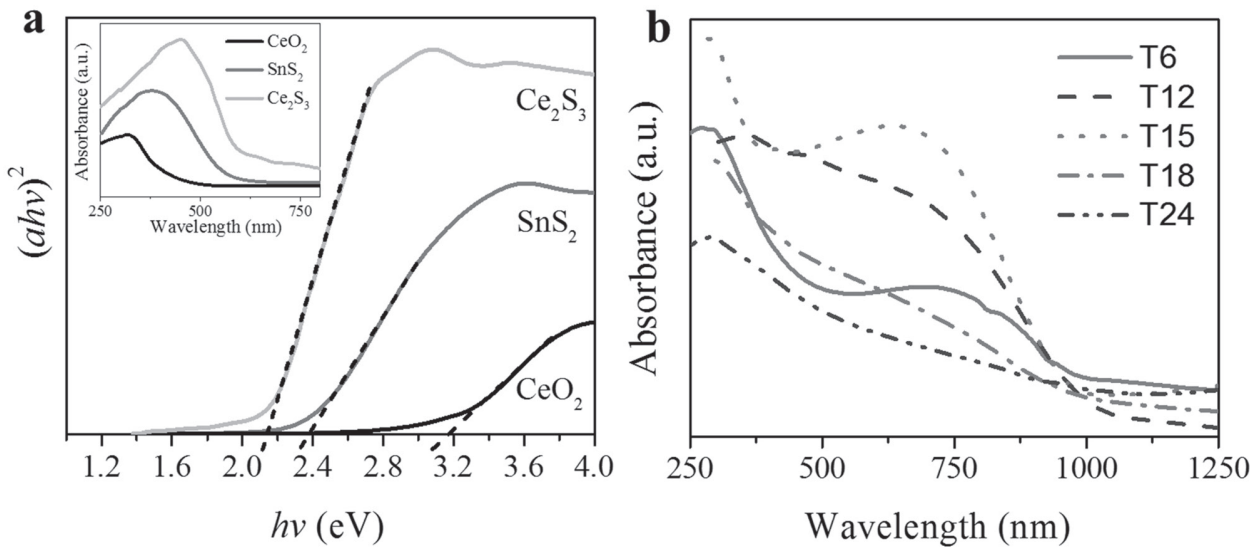

Figure 4. Band gaps of various photocatalysts. a) UV/vis/NIR diffusive reflectance absorption spectra (inset) and estimated band gap potential of synthesized $\mathrm{CeO}_{2}(3.16 \mathrm{eV}), \mathrm{SnS}_{2}(2.38 \mathrm{eV})$, and $\mathrm{Ce}_{2} \mathrm{~S}_{3}(2.14 \mathrm{eV})$. b) UV/vis/NIR diffusive reflectance absorption spectra of the different samples.

of the tangent to the $h v$ axis can provide a good approximation of the band gap energy. Accordingly, the band gap values of $\mathrm{Ce}_{2} \mathrm{~S}_{3}, \mathrm{SnS}_{2}$, and $\mathrm{CeO}_{2}$ are found to be $2.14,2.38$, and $3.16 \mathrm{eV}$, respectively (Figure $4 \mathrm{a}$ ). Then the top of the $\mathrm{VB}$ and the bottom of the $\mathrm{CB}$ of $\mathrm{Ce}_{2} \mathrm{~S}_{3}, \mathrm{SnS}_{2}$, and $\mathrm{CeO}_{2}$ can be calculated according to the empirical equation as follows: ${ }^{[20]}$

$E_{\mathrm{VB}}=X-E_{\mathrm{e}}+\frac{1}{2} E_{\mathrm{g}}$

$E_{\mathrm{CB}}=E_{\mathrm{VB}}-E_{\mathrm{g}}$

Where, $E_{\mathrm{VB}}$ is the VB edge potential and $E_{\mathrm{CB}}$ is the CB edge potential versus normal hydrogen electrode (NHE), $X$ is the absolute electronegativity (Mulliken electronegativity) of the semiconductor, equal to the geometric mean of Pearson absolute electronegativity of atoms in semiconductor (Supporting information, Calculation), $E_{\mathrm{e}}$ is the standard hydrogen electrode potential $\left(E_{\mathrm{e}}=4.5 \mathrm{eV}\right)$, and $E_{\mathrm{g}}$ is the band gap energy of the semiconductor. Accordingly, the $E_{\mathrm{VB}}$ and $E_{\mathrm{CB}}$ are calculated to be 2.19 and $-0.19 \mathrm{eV}$ for $\mathrm{SnS}_{2}, 2.75$ and $-0.41 \mathrm{eV}$ for $\mathrm{CeO}_{2}$, as well as 1.34 and $-0.80 \mathrm{eV}$ for $\mathrm{Ce}_{2} \mathrm{~S}_{3}$, respectively (Supporting information, Calculation).

Compared with the absorption spectra of the pristine $\mathrm{Ce}_{2} \mathrm{~S}_{3}$, $\mathrm{SnS}_{2}$, and $\mathrm{CeO}_{2}$ (Figure 4a, inset), an incredibly strong absorption ranging from 250 to $1000 \mathrm{~nm}$ is exhibited by the heterostructures samples (Figure 4b). The improved visible light absorption of T6 and T12 and T15 may be attributed to the ultrathin intermediate layer of $\mathrm{Ce}_{2} \mathrm{~S}_{3}$. According to the report by $\mathrm{Gu}$ et al.,[23] annealing could lead to a hybridized, heterogeneous surface layer as a cost-effective catalytic and protective interface. It is supposed that the interpenetration of $\mathrm{SnS}_{2}$ nanosheet, $\mathrm{Ce}_{2} \mathrm{~S}_{3}$ nanoribbons, and $\mathrm{CeO}_{2}$ nanoparticles caused by annealing produced doping effect and greatly expanded the available radiation for photocatalytic water splitting. The energy band configuration and the process of generating photoinduced charge carriers in $\mathrm{SnS}_{2}-\mathrm{Ce}_{2} \mathrm{~S}_{3}-\mathrm{CeO}_{2}$ heterostructures are clearly depicted in the schematic, as can be seen in Figure 1f. The presence of $\mathrm{Ce}_{2} \mathrm{~S}_{3}$ gives rise to the construction of Type-II band structure (between $\mathrm{SnS}_{2}-\mathrm{Ce}_{2} \mathrm{~S}_{3}$ and $\mathrm{Ce}_{2} \mathrm{~S}_{3}-\mathrm{CeO}_{2}$ ), which would otherwise behave like mere of Type-I band alignment (between $\mathrm{SnS}_{2}$ and $\mathrm{CeO}_{2}$ ). Thus, the very good performance of hydrogen production can be expected, as a result of such TypeII band alignment.

Photocatalytic water splitting over various catalysts was evaluated by monitoring the $\mathrm{H}_{2}$ evolution from aqueous solutions containing $100 \mathrm{~mL}$ deionized water with $10 \%$ triethanolamine (TEOA) sacrificial agents. The measurement was performed under simulated sunlight at room temperature and the amount of evolved $\mathrm{H}_{2}$ was quantified by gas chromatography (GC) connected with the photocatalytic reactor. Figure 5a shows the time course of hydrogen evolution through direct photocatalysis with different samples. Pristine $\mathrm{CeO}_{2}$ and $\mathrm{SnS}_{2}$ demonstrate a certain photocatalysis under light illumination. The rate of $\mathrm{H}_{2}$ evolution is varied from T6 to T24. It is evident that T15 shows the best hydrogen evolution rate of about $240 \mu \mathrm{mol} \mathrm{g}-1 \mathrm{~h}^{-1}$, which is around 10 times of that of pristine $\mathrm{SnS}_{2}\left(24.8 \mu \mathrm{mol} \mathrm{g}^{-1} \mathrm{~h}^{-1}\right)$. However, the performance of the T24 $\left(69.0 \mu \mathrm{mol} \mathrm{g}^{-1} \mathrm{~h}^{-1}\right)$ even becomes less than that of T6 $\left(84.5 \mu \mathrm{mol} \mathrm{g} \mathrm{g}^{-1} \mathrm{~h}^{-1}\right)$. Our characterization results confirmed that the different reaction time can be associated with the different content of $\mathrm{Ce}_{2} \mathrm{~S}_{3}$ and $\mathrm{CeO}_{2}$. On one hand, when the reaction time is short, the content of $\mathrm{CeO}_{2}$ becomes too low to entirely cover the surface of $\mathrm{Ce}_{2} \mathrm{~S}_{3}$ nanoribbons, thus leading to an unsatisfactory performance of catalyzing $\mathrm{H}_{2}$ evolution. On the other hand, the hindering of light absorption would occur if excess $\mathrm{CeO}_{2}$ nanoparticles cover the surface of the $\mathrm{SnS}_{2}-\mathrm{Ce}_{2} \mathrm{~S}_{3}$ system. Thus, an optimum amount of $\mathrm{CeO}_{2}$ is beneficial for the intended purpose. Furthermore, the stability of T15 was evaluated. Figure $5 \mathrm{~b}$ shows the cycling measurements of $\mathrm{H}_{2}$ generation under light illumination for a continuous $50 \mathrm{~h}$ test, the sample exhibits a feasible ability for water splitting under simulated sunlight.

\section{Conclusion}

In summary, a $\mathrm{SnS}_{2}-\mathrm{Ce}_{2} \mathrm{~S}_{3}-\mathrm{CeO}_{2}$ heterostructure was synthesized on $\mathrm{CF}$ with a two-step solvothermal method. Impressively, the introduction of $\mathrm{Ce}_{2} \mathrm{~S}_{3}$ made a crucially important change in the band alignment from Type-I $\left(\mathrm{SnS}_{2}\right.$ and $\left.\mathrm{CeO}_{2}\right)$ to Type-II $\left(\mathrm{SnS}_{2}-\mathrm{Ce}_{2} \mathrm{~S}_{3}\right.$ and $\left.\mathrm{Ce}_{2} \mathrm{~S}_{3}-\mathrm{CeO}_{2}\right)$ wherein the enhanced absorption of visible light is more pronounced. By controlling the reaction time, the degree of $\mathrm{CeO}_{2}$ coverage on the surface 
$\mathbf{a}$

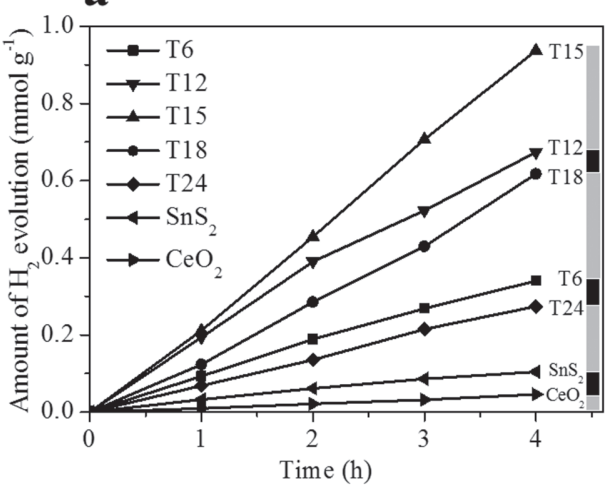

b

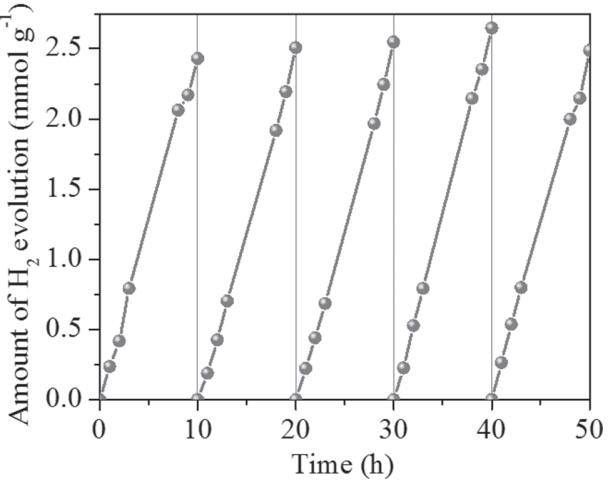

Figure 5. Photocatalytic hydrogen production based on various photocatalysts. a) Plots of hydrogen evolution through direct photocatalytic water splitting for different samples, under simulated sunlight in $100 \mathrm{~mL}$ deionized water with $10 \%$ TEOA as sacrificial agent. b) Cycling measurements of hydrogen gas generation of the T15 sample.

of $\mathrm{Ce}_{2} \mathrm{~S}_{3}$ can be optimized. And the T15 sample performed the best ability for $\mathrm{H}_{2}$ evolution with good stability. Our material combines the advantages of suitable energy band of sulfide and appreciable chemical stability of oxides making it perform well in photocatalyzing $\mathrm{H}_{2}$ evolution. Given this summative benefit, we believe that heterostructures built on the same trend can provide a new prospect for water splitting.

\section{Experimental Section}

Synthesis of Pristine $\mathrm{SnS}_{2}, \mathrm{Ce}_{2} \mathrm{~S}_{3}$, and $\mathrm{CeO}_{2}: \mathrm{SnS}_{2}$ nanosheets were grown on CF using a solvothermal method. In brief, the CF was cleaned thoroughly and put into $40 \mathrm{~mL}$ ethanolic solution containing $20 \mathrm{mmol} \mathrm{L}^{-1}$ ( $\mathrm{m} \mathrm{M}$ ) of $\mathrm{SnCl}_{4}$ and $60 \times 10^{-3} \mathrm{M}$ of thioacetamide $\left(\mathrm{CH}_{3} \mathrm{CSNH}_{2}\right)$. The content was then sealed and treated at $75{ }^{\circ} \mathrm{C}$ for $6 \mathrm{~h}$. Finally, the $\mathrm{CF}$ was washed and dried to obtain vertically oriented $\mathrm{SnS}_{2}$ nanosheets. The pristine $\mathrm{Ce}_{2} \mathrm{~S}_{3}$ was synthesized by the same method with $\mathrm{SnS}_{2}$, but using $20 \times 10^{-3} \mathrm{M}$ of $\mathrm{Ce}\left(\mathrm{NO}_{3}\right)_{3}$ instead of the $20 \times 10^{-3} \mathrm{M}$ of $\mathrm{SnCl}_{4}$. The pristine $\mathrm{CeO}_{2}$ was synthesized in water with $20 \times 10^{-3} \mathrm{M}$ of $\mathrm{Ce}\left(\mathrm{NO}_{3}\right)_{3}$ and $80 \times 10^{-3} \mathrm{M}$ of $\mathrm{HMT}$ at $75{ }^{\circ} \mathrm{C}$ for $12 \mathrm{~h}$

Decoration of $\mathrm{Ce}_{2} \mathrm{~S}_{3}$ and $\mathrm{CeO}_{2}$ on $\mathrm{SnS}_{2}$ Nanosheets: The as obtained $\mathrm{SnS}_{2} / \mathrm{CF}$ nanosheets was immersed in the solution (ethanol and water, volume ratio, 1:1) with $20 \times 10^{-3} \mathrm{M}$ of $\mathrm{Ce}\left(\mathrm{NO}_{3}\right)_{3}, 80 \times 10^{-3} \mathrm{M}$ of $\mathrm{HMT}$, and $5 \times 10^{-3} \mathrm{M}$ of thioacetamide $\left(\mathrm{CH}_{3} \mathrm{CSNH}_{2}\right)$. The content was then sealed and treated at $75{ }^{\circ} \mathrm{C}$ for $6,12,15,18$, and $24 \mathrm{~h}$ (Samples T6, T12, $\mathrm{T} 15, \mathrm{~T} 18$, and T24). The process of reaction is speculated as following: first, the $\mathrm{Ce}_{2} \mathrm{~S}_{3}$ nanoribbons were formed on the surface of the $\mathrm{SnS}_{2}$ nanosheet by the reaction $\mathrm{Ce}\left(\mathrm{NO}_{3}\right)_{3}$ and thioacetamide (providing $\mathrm{S}^{2-}$ by thermal decomposition). With the increase of reaction time, a protective layer of $\mathrm{Ce}(\mathrm{OH})_{3}$, produced by reaction between $\mathrm{Ce}\left(\mathrm{NO}_{3}\right)_{3}$ and HMT (providing $\mathrm{OH}^{-}$by thermal decomposition), covered the nanoribbons of $\mathrm{Ce}_{2} \mathrm{~S}_{3}$. And then the $\mathrm{Ce}(\mathrm{OH})_{3}$ turned into $\mathrm{CeO}_{2}$ quickly because of the air in the solution. Next, it was taken out and placed in the center of Ar saturated tube furnace for annealing at $350{ }^{\circ} \mathrm{C}$ for $2 \mathrm{~h}$. Finally, the sandwiched structure of $\mathrm{SnS}_{2}-\mathrm{Ce}_{2} \mathrm{~S}_{3}-\mathrm{CeO}_{2}$ was obtained.

Characterization of Materials: SEM images were obtained from a Hitachi S4800 field-emission scanning electron micro analyzer with an accelerating voltage of $20 \mathrm{kV}$. HRTEM images and SAED patterns were obtained via employing a Tecnai G2 F20 with beam energy of $200 \mathrm{keV}$. XRD were obtained from a D/MAX-TTRIII(CBO) system using a Cu-K $\alpha$ radiation $(\lambda=1.5418 \AA$ ). Raman spectroscopy was measured at room temperature on an inVia Renishaw system at the excitation line of $532 \mathrm{~nm}$. The Raman band of Si at $520 \mathrm{~cm}^{-1}$ was used as a reference to calibrate the spectrometer. The chemical composition of the as-prepared samples was examined with XPS (ESCALAB250Xi). UV/Vis/NIR spectra were recorded on a Lambda 950 spectrophotometer equipped with an integrating sphere.

Measurement of Photocatalytic $\mathrm{H}_{2}$ Evolution: Photocatalytic water splitting experiments were conducted in a $500 \mathrm{~mL}$ cylinder quartz reactor at ambient temperature. A $300 \mathrm{~W}$ xenon lamp (installed with a filter of AM 1.5) used as a light source. In a typical $\mathrm{H}_{2}$ evolution experiment, the prepared photocatalyst was placed at the bottom of reactor containing $100 \mathrm{~mL}$ aqueous solution containing 10\% TEOA. Before irradiation, the system was vacuumed for about $30 \mathrm{~min}$ to remove the air inside and to ensure that the system was under the anaerobic condition. A certain amount of gas was intermittently sampled and analyzed by gas chromatography (GC7900, Shimadzu, Japan, TCD, nitrogen as a carrier gas and $5 \AA$ molecular sieve column) by using Ar as a carrier gas. A base-line was recorded for each test before exposure to xenon lamp.

\section{Supporting Information}

Supporting Information is available from the Wiley Online Library or from the author.

\section{Acknowledgements}

This work was supported by Ministry of Science and Technology of China (Grant No. 2016YFA0200700), National Natural Science Foundation of China (Grant Nos. 21373065, 61474033, 61574050, and 11674072), Strategic Priority Research Program of the Chinese Academy of Sciences (Grant No. XDA09040201), and CAS Key Laboratory of Nanosystem and Hierarchical Fabrication. The authors also gratefully acknowledge the support of Youth Innovation Promotion Association CAS.

\section{Conflict of Interest}

The authors declare no conflict of interest.

\section{Keywords}

ceria, cerium sulfide, heterostructures, $\mathrm{SnS}_{2}$, water splitting

Received: June 26, 2017

Revised: July 21, 2017

Published online: 
[1] a) S. Moniz, S. A. Shevlin, D. J. Martin, Z. X. Guo, J. Tang, Energy Environ. Sci. 2015, 8, 731; b) X. Meng, L. Liu, S. Ouyang, H. Xu, D. Wang, N. Zhao, J. Ye, Adv. Mater. 2016, 28, 6781; c) X. Chen, Z. Zhang, L. Chi, A. K. Nair, W. Shangguan, Z. Jiang, Nano-Micro Lett. 2016, 8, 1

[2] X. Chen, L. Liu, Y. Y. Peter, S. S. Mao, Science 2011, 331, 746.

[3] a) S. U. Khan, M. Shahry, W. B. Ingler, Science 2002, 297, 2243; b) L. Li, J. Yan, T. Wang, Z. J. Zhao, J. Zhang, J. Gong, N. Guan, Nat. Commun. 2015, 6, 5881; c) M. Ge, Q. Li, C. Cao, J. Huang, S. Li, S. Zhang, Z. Chen, K. Zhang, S. S. Deyab, Y. Lai, Adv. Sci. 2017, 4, 1600152.

[4] a) A. Wolcott, W. A. Smith, T. R. Kuykendall, Y. Zhao, J. Z. Zhang, Adv. Funct. Mater. 2009, 19, 1849; b) X. Zhang, Y. Liu, Z. Kang, ACS Appl. Mater. Interfaces 2014, 6, 4480; c) M. Baek, D. Kim, K. Yong, ACS Appl. Mater. Interfaces 2017, 9, 2317.

[5] a) N. Bao, L. Shen, T. Takata, K. Domen, Chem. Mater. 2007, 20, 110; b) T. Simon, N. Bouchonville, M. J. Berr, A. Vaneski, A. Adrović, D. Volbers, R. Wyrwich, M. Döblinger, A. S. Susha, A. L. Rogach, Nat. Mater. 2014, 13, 1013; c) X. L. Zheng, J. P. Song, T. Ling, Z. P. Hu, P. F. Yin, K. Davey, X. W. Du, S. Z. Qiao, Adv. Mater. 2016 28, 4935.

[6] a) S. J. Moniz, S. A. Shevlin, D. J. Martin, Z. X. Guo, J. Tang, Energy Environ. Sci. 2015, 8, 731; b) A. Iwase, S. Yoshino, T. Takayama, Y. H. Ng, R. Amal, A. Kudo, J. Am. Chem. Soc. 2016, 138, 10260; c) Q. Wang, T. Hisatomi, Q. Jia, H. Tokudome, M. Zhong, C. Wang, Z. Pan, T. Takata, M. Nakabayashi, N. Shibata, Nat. Mater. 2016, 15, 611.

[7] a) C. Tan, H. Zhang, Nat. Commun. 2015, 6, 7873; b) C. Tan, X. Cao, X. J. Wu, Q. He, J. Yang, X. Zhang, J. Chen, W. Zhao, S. Han, G. H. Nam, Chem. Rev. 2017, 117, 6225 .

[8] a) A. K. Singh, K. Mathew, H. L. Zhuang, R. G. Hennig, J. Phys. Chem. Lett. 2015, 6, 1087; b) X. Zhang, X. Zhao, D. Wu, Y. Jing, Z. Zhou, Adv. Sci. 2016, 3, 1600062.

[9] a) B. Tian, Z. Li, W. L. Zhen, G. X. Lu, J. Phys. Chem. C 2016, 120, 6409; b) D. Mateo, I. Esteve-Adell, J. Albero, J. F. S. Royo, A. Primo, H. Garcia, Nat. Commun. 2016, 7, 11819.
[10] K. Zhang, J. K. Kim, M. Ma, S. Y. Yim, C. L. Lee, H. Shin, J. H. Park, Adv. Funct. Mater. 2016, 26, 4527.

[11] a) X. C. Wang, K. Maeda, A. Thomas, K. Takanabe, G. Xin, J. M. Carlsson, K. Domen, M. Antonietti, Nat. Mater. 2009, 8, 76; b) J. Zhang, M. Zhang, C. Yang, X. Wang, Adv.Mater. 2014, 26, 4121; c) J. Liu, Y. Liu, N. Liu, Y. Han, X. Zhang, H. Huang, Y. Lifshitz, S. T. Lee, J. Zhong, Z. Kang, Science 2015, 347, 970; d) Q. Han, B. Wang, J. Gao, Z. Cheng, Y. Zhao, Z. Zhang, L. Qu, ACS Nano 2016, 10, 2745.

[12] Y. Huang, H. X. Deng, K. Xu, Z. X. Wang, Q. S. Wang, F. M. Wang, F. Wang, X. Y. Zhan, S. S. Li, J. W. Luo, Nanoscale 2015, 7, 14093.

[13] a) J. H. Ahn, M. J. Lee, H. Heo, J. H. Sung, K. Kim, H. Hwang, M. H. Jo, Nano Lett. 2015, 15, 3703; b) L. A. Burton, D. Colombara, R. D. Abellon, F. C. Grozema, L. M. Peter, T. J. Savenije, G. Dennler, A. Walsh, Chem. Mater. 2013, 25, 4908.

[14] a) J. Yu, C. Y. Xu, F. X. Ma, S. P. Hu, Y. W. Zhang, L. Zhen, ACS Appl. Mater. Interfaces 2014, 6, 22370; b) Y. Sun, H. Cheng, S. Gao, Z. Sun, Q. Liu, Q. Liu, F. Lei, T. Yao, J. He, S. Wei, Angew. Chem. Int. Ed. 2012, 51, 8727.

[15] S. Chen, H. Zhang, X. Fu, Y. Hu, Appl. Surf. Sci. 2013, 275, 3351.

[16] Z. Cheng, F. Wang, T. A. Shifa, K. Liu, Y. Huang, Q. Liu, C. Jiang, J. He, Appl. Phys. Lett. 2016, 109, 053905.

[17] G. Lucovsky, J. Mikkelsen Jr., W. Liang, R. White, R. Martin, Phys. Rev. B 1976, 14, 1663.

[18] S. Putla, M. H. Amin, B. M. Reddy, A. Nafady, K. A. Al Farhan, S. K. Bhargava, ACS Appl. Mater. Interfaces 2015, 7, 16525.

[19] B. Kolesov, A. Kamarzin, V. Sokolov, J. Struct. Chem. 1997, 38, 544.

[20] Y. C. Zhang, Z. N. Du, K. W. Li, M. Zhang, D. D. Dionysiou, ACS Appl. Mater. Interfaces 2011, 3, 1528.

[21] P. Chen, Y. Su, H. Liu, Y. Wang, ACS Appl. Mater. Interfaces 2013, 5, 12073.

[22] H. Zhong, G. Yang, H. Song, Q. Liao, H. Cui, P. Shen, C. X. Wang, J. Phys. Chem. C 2012, 116, 9319.

[23] J. Gu, J. A. Aguiar, S. Ferrere, K. X. Steirer, Y. Yan, C. Xiao, J. L. Young, M. Al-Jassim, N. R. Neale, J. A. Turner, Nat. Energy 2017, 2, 16192. 